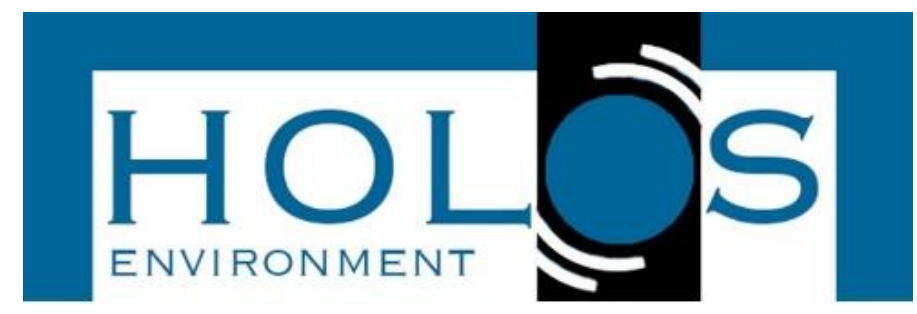

\title{
ANÁLISE DA GEODINÂMICA EXTERNA DO RIO ATINGIDO PELO ROMPIMENTO DA BARRAGEM FUNDÃO, MARIANA - MG: TRECHO ENTRE BENTO RODRIGUES E BARRA LONGA
}

\section{ANALYSIS OF THE EXTERNAL GEODYNAMICS OF THE RIVER DAMAGED BY THE FUNDÃO DAM BREAK, MARIANA - MG: BETWEEN BENTO RODRIGUES AND BARRA LONGA}

\author{
Cristhian Filgueira Dias ${ }^{1}$; Luisa Oliveira Duarte ${ }^{1}$; Mayara Pereira Cabanhe ${ }^{1}$; \\ Eliane Maria Vieira ${ }^{1}$
}

Artigo recebido em: 05/05/2019 e aceito para publicação em: 24/06/2019.

DOI: http://dx.doi.org/10.14295/holos.v19i3.12338

\begin{abstract}
Resumo: O presente trabalho avalia a geodinâmica externa do Rio Gualaxo do Norte, trecho de Bento Rodrigues até Barra Longa, após o rompimento da barragem Fundão, em Mariana. A bacia hidrográfica do Rio Doce foi contaminada e consequentemente os parâmetros físico-químicos da bacia foram alterados, acarretando na mudança da cor, turbidez, entre outros, impactando negativamente diversos cursos d'águas. Devido ao mar de lama contendo os rejeitos da mineração, o curso natural do trecho do rio em estudo foi modificado, bem como a biota, incluindo a vegetação próxima aos rios, também conhecida como mata de galeria. Os prejuízos causados foram diversos, acarretando em mudanças na superfície do rio por onde a onda de rejeitos passou. Desta maneira, utilizando imagens multitemporais obtidas pelo Google Earth e o sistema de informação geográfica ArcGis, foi possível analisar e identificar as transformações ocorridas, através de mapas, que demonstram áreas onde foram nítidas as alterações no leito do rio em termos de deslocamento e dimensões, o que afeta diretamente todo o ecossistema local.
\end{abstract}

Palavras-chave: Geodinâmica externa. Rejeitos de mineração. ArcGIS. Curso d'água.

Abstract: The present work evaluates the external geodynamics of the Rio Gualaxo do Norte, from Bento Rodrigues to Barra Longa, after the rupture of the Fundão dam in Mariana. The watershed of the Doce River was contaminated and consequently the physico-chemical parameters of the basin were altered, causing in the change of color, turbidity, among others, negatively impacting several water courses. Due to the muddy sea containing the mining tailings, the natural course of the stretch of river under study was modified, as well as the biota, including vegetation near the rivers, also known as gallery forest. The damages caused were diverse, leading to changes in the surface of the river where the tailings wave passed. In this way, using multitemporal images obtained by Google Earth and the geographic information system ArcGis, it was possible to analyze and identify the transformations that occurred through maps that demonstrate areas where the changes in the river bed in terms of displacement and dimensions were clear, which directly affects the entire local ecosystem.

Keywords: External geodynamics, mining tailings, ArcGIS, watercourse.

\footnotetext{
${ }^{1}$ Universidade Federal de Itajubá (UNIFEI), Itajubá, MG. E-mail: (cristhiandias3@gmail.com, luluduarte@gmail.com, mayara.cabanhe@gmail.com, elianevvv@yahoo.com.br)
} 


\section{INTRODUÇÃO}

As alterações no meio decorrente de ações humanas têm ganhado tamanhas proporções que este já é considerado como um agente geológico-morfoológico, definindo um período geológico o Tecnógeno, uma época do Quinário, período que sucederia o Quaternário na escala do tempo geológico (OLIVEIRA et al., 2005). Tais alterações são decorrentes da forma como a sociedade se estabeleceu, contudo, ao longo do século $\mathrm{XX}$ e, mais particularmente, nos últimos 50 anos a exposição das pessoas aos riscos de desastres vem crescendo no Brasil e no mundo mais rapidamente do que as capacidades de redução da vulnerabilidade, resultando em intensos e extensos (no tempo e no espaço) impactos (FREITAS, SILVA e MENEZES, 2016).

Neste contexto, o desastre do rompimento da barragem de rejeitos de Fundão, da empresa Samarco, ocorrido em 2015, no subdistrito de Bento Rodrigues, no município de Mariana - MG, é considerado mais uma das grandes e graves tragédias socioambientais do Brasil. O impacto do desastre foi classificado no Decreto oㅜ 46.892/2015 do Grupo da Força Tarefa do Governo do Estado de Minas Gerais (2016), em duas escalas uma microrregional, considerando os efeitos sobre os municípios de Mariana, Barra Longa, Rio Doce e Santa Cruz do Escalvado e uma macrorregional considerando toda a calha ao longo do Rio Doce.

Neto et al. (2018), ainda salienta que os prejuízos sofridos não se restringiram ao subdistrito de Mariana (local da Barragem), mas que alcançam escalas nacional e internacional, visto que muitos efeitos não foram em sua totalidade detectados. A grande quantidade de lama provocou danos ambientais intensos comprometendo solo, cobertura vegetal e rios. Dentre esses, pode-se ressaltar a interferência na dinâmica dos recursos hídricos, devido à invasão de lama no leito do rio. Essa interferência gera diversos problemas, desde a acentuação do processo de assoreamento em vários pontos da extensão do rio, até o acúmulo de rejeitos de minério às margens, que pode causar danificação na vegetação (Decreto № 46.892/2015, 2016). Além disso, houve modificação do trajeto dos rios atingidos, como o Rio Gualaxo do Norte, o primeiro afetado, que é um subafluente do Rio Doce uma importante bacia hidrográfica.

Conforme Gonçalves, Francisco e Vieira (2013), a utilização de produtos e técnicas de sensoriamento remoto e geoprocessamento nas análises ambientais 
têm se tornado uma prática cada vez mais frequente entre as diversas áreas de pesquisa. Dessa forma, há grande contribuição na eficiência das análises de áreas degradadas e na identificação dos possíveis fatores da degradação.

Em função da magnitude do desastre ocorrido na barragem de Fundão, a tecnologia de Sensoriamento Remoto torna-se necessária para a compreensão da dimensão espacial do mesmo, uma vez que, as imagens orbitais, em função das suas características (resolução espacial, temporal, radiométrica e espectral), apresentam facilidade de acesso e pela visão sinótica proporcionada, caracterizando-se como grandes aliadas no estudo, monitoramento, prevenção e gerenciamento de desastres naturais (SILVA et al., 2018).

Realizar detecções de mudanças de características da superfície da Terra é importante para a compreensão tanto da dinâmica dos fenômenos quanto para a previsão dos impactos, bem como para o apoio na tomada de decisões. Durante as últimas décadas foram desenvolvidas várias técnicas de detecção de mudanças a partir de imagens, dentre elas as baseadas em imagens de Sensoriamento Remoto (CALDEIRA, 2016), assim, para o reconhecimento das mudanças são utilizados conjuntos de dados multi-temporais que permite a análise do fenômeno de interesse.

De acordo com Zani et al. (2011), o monitoramento desses remanescentes florestais, visando sua preservação e a manutenção de suas funções ecológicas é de suma importância. $O$ sucesso desse monitoramento está vinculado à realização de mapeamentos contínuos (com escalas compatíveis com as características da área de estudo). É nesse sentido que as diversas técnicas de Sensoriamento Remoto e Sistemas de Informações Geográficas (SIG) na construção e atualização de mapeamentos, referenciados à cartografia temática ou de base, se destacam.

Os estudos sobre detecção de mudança é definido como o reconhecimento de alterações nos padrões característicos de determinado alvo nas imagens em certo um período de tempo. Como fonte de dados neste tipo de pesquisa, se tem os Sensores orbitais que fornecem informações da superfície terrestre, essas informações são colocadas em um SIG de onde consegue-se inferir resultados que podem auxiliar no monitoramento de ambientes naturais ou urbanos (VIEGAS et al., 2013). A premissa básica é a de que todas as alterações na cobertura terrestre deverão resultar em mudanças nos valores de radiância.

Segundo Coppin et al. (2004), a diferença da análise bi-temporal, quando são utilizadas apenas imagens de duas datas, da utilização de três ou mais datas, é que 
esta permite estabelecer as trajetórias evolutivas do uso e cobertura da terra. A análise da trajetória temporal é uma importante ferramenta para identificar o histórico de cada uso e cobertura da terra ao longo do tempo, servindo como subsídio para a compreensão e localização da idade de cada uma das mudanças e, consequentemente, o seu grau de degradação. Segundo Mertens \& Lambin (2000), as trajetórias podem representar mudanças irreversíveis, reversíveis ou cíclicas. Assim, reconhecendo o processo de degradação de forma indulgente, através das imagens, o estudo do mesmo se mostra eficiente para regiões próximas e distantes, sem a necessidade de ir ao local.

O presente trabalho utiliza imagens multitemporais, obtidas pelo software Google Earth, com o objetivo de analisar os impactos relacionados a um trecho dos rios atingidos pelo rompimento da barragem Fundão, no subdistrito de Bento Rodrigues, no município de Mariana - MG. Dessa forma, será possível identificar as principais sequências de mudanças no trajeto do rio após o desastre, bem como a zona nas margens do rio afetada, através da análise espacial das imagens multitemporais.

\section{MATERIAL E MÉTODOS}

A área escolhida para se analisar, está localizada no subdistrito Bento Rodrigues no município de Mariana - MG. O objeto de estudo corresponde a um trecho do Rio Gualaxo do Norte, sendo este rio localizado no município de Mariana - MG e subafluente do Rio Doce.

O trecho em estudo possui aproximadamente $80 \mathrm{~km}$ de extensão, sendo o ponto inicial do trecho no subdistrito de Bento Rodrigues, no município de Mariana MG, com coordenadas geográficas $662876.01 \mathrm{~m} \mathrm{E} 7762036.76 \mathrm{~m} \mathrm{~S}$, e o ponto final no município de Barra Longa - MG com coordenadas geográficas $704052.32 \mathrm{~m} \mathrm{E}$ $7755996.34 \mathrm{~m} \mathrm{~S}$. Para se identificar as mudanças comportamentais do rio após o desastre, inicialmente foi utilizada a ferramenta Google Earth, criando três polígonos, um relacionado ao rio antes do desastre, na data de 20/07/2015, outro do rio com um tempo após o rompimento da barragem, na data de 09/08/2016 e por último um polígono para as margens afetadas juntamente com o rio na mesma data do anterior. 
Figura 01 - Percurso dos rejeitos de minério do rompimento da barragem Fundão do município de Mariana, MG

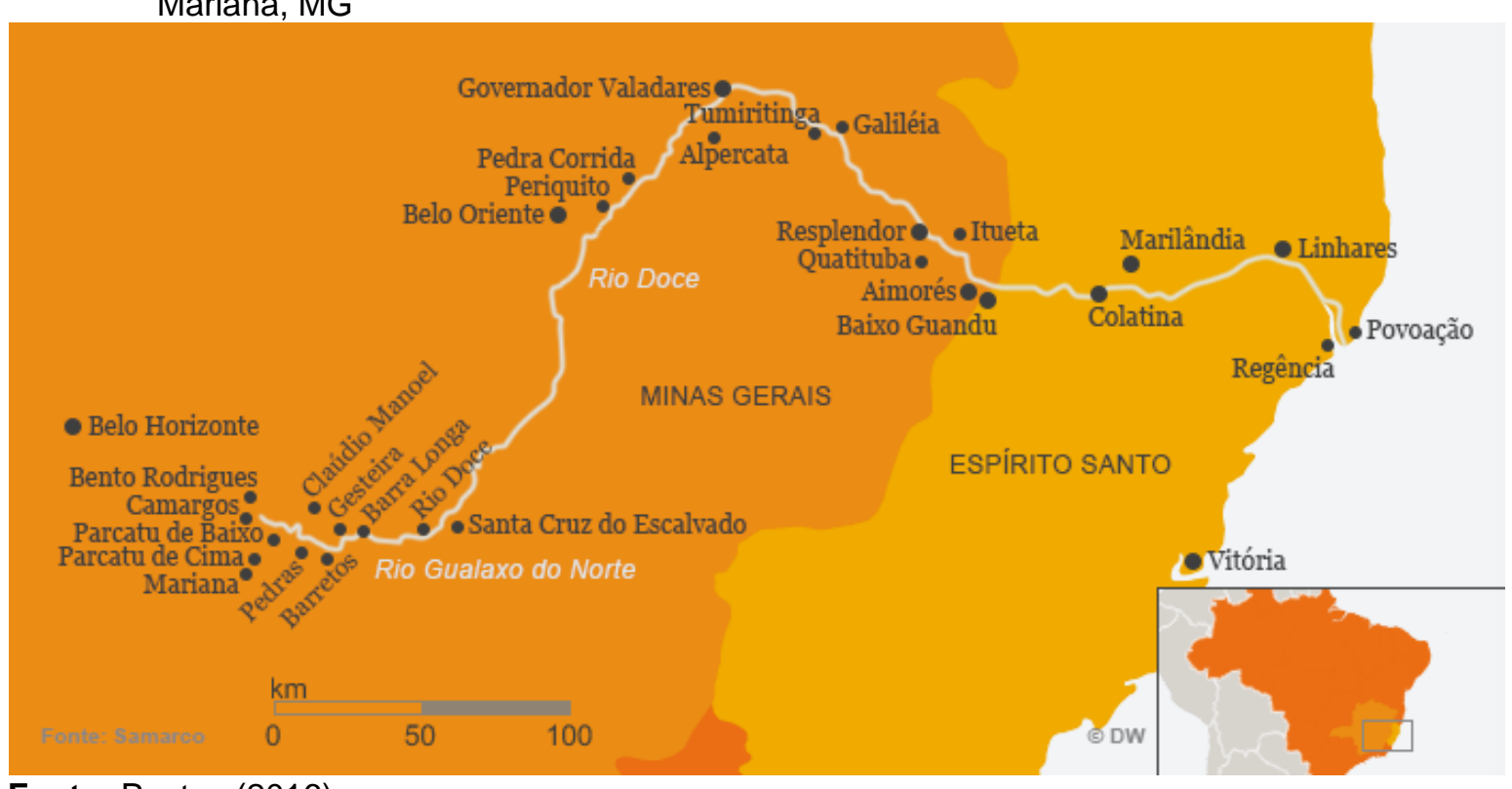

Fonte: Pontes (2016)

Figura 02 - Trecho em estudo: com início em Bento Rodrigues e final em Barra Longa

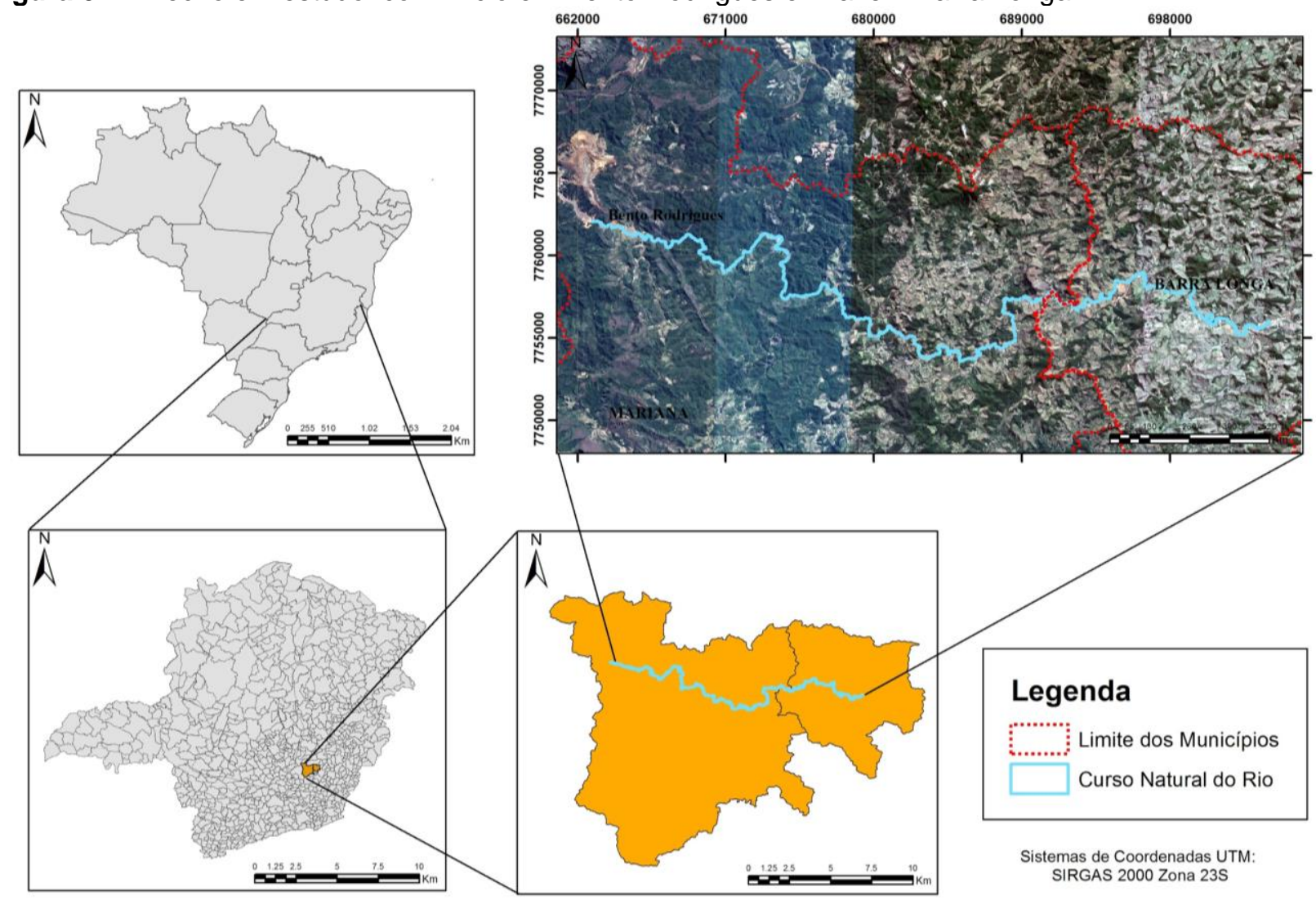

Fonte: Autores deste trabalho

Depois de se obter os três polígonos, sendo estes salvos em formato $\mathrm{Kml}$, para se exibir dados geográficos, os arquivos foram gerados em formato shapefile e 
abertos no software ArcGIS, uma ferramenta SIG. Definiu-se o sistema de projeção Universal Transversa de Mercator (UTM) SIRGAS 2000 Zona 23 S. Após este procedimento, com as três camadas definidas (Curso Natural, Curso Modificado e Margens Atingidas), essas foram sobrepostas a fim de se analisar as mudanças relacionadas ao trajeto do rio e ao rastro nas margens do rio deixado pela passagem da lama de rejeitos de minério. Através da ferramenta de geoprocessamento, interseção, foi calculada a área de arraste que define as perdas ambientais causadas pelo desastre.

A imagem com o trecho em estudo foi salva em formato jpg com resolução de 300pi no Google Earth Pro, e importada no ArcGIS, onde foi georreferenciada e os polígonos sobrepostos a ela para que pudesse ser desenvolvido os mapas. Para o desenvolvimento do layout dos mapas, foram definidas cores representativas para cada polígono indicando as suas respectivas camadas.

\section{RESULTADOS E DISCUSSÃO}

Para se analisar a geodinâmica externa do Rio Gualaxo do Norte, foram feitos três mapas, contendo os cursos naturais e modificados do rio em questão, sendo que trecho estudado foi Bento Rodrigues à Barra Longa. Através desses levantamentos, foi possível identificar as mudanças do rio, após o rompimento da barragem Fundão, em Mariana, incluindo também a margem do mesmo.

O desastre ambiental em estudo ocasionou danos às matas ciliares remanescentes, que foi fragmentada após o ocorrido, já os sedimentos (lama de rejeito da exploração de minério de ferro) contribuiu imediatamente para o soterramento de organismos de portes pequenos do sub-bosque e causando a supressão indivíduos arbóreos. Outro fator a ser considerado é que os rejeitos de mineração de ferro possui potencial poluidor, podendo afetar o solo por se tratarem de material inerte sem matéria orgânica, causando desestruturação química e afetando o $\mathrm{Ph}$ do solo. Com isso, pode-se haver uma contrariedade na recuperação e no crescimento de espécies endêmicas, tendo a possibilidade de uma variação, de médio à longo prazo, na vegetação, facultando o surgimento de biotas diferentes dos biomas nativos (BRASIL, 2015, p. 10-11)"

A Figura 3, demonstra o curso natural do rio, antes do rompimento. Em cada trecho, onde houve bastante alterações, foi dado um zoom para que se pudesse vi- 
sualizar, de forma mais clara, como o era o percurso do rio antes do acontecimento. Vê-se que a área onde rio passava é bem menor quando comparada com a área atual, que será discutida mais à frente.

Figura 03 - Rio Gualaxo do Norte antes do rompimento da Barragem Fundão: Trecho Bento Rodrigues - Barra Longa

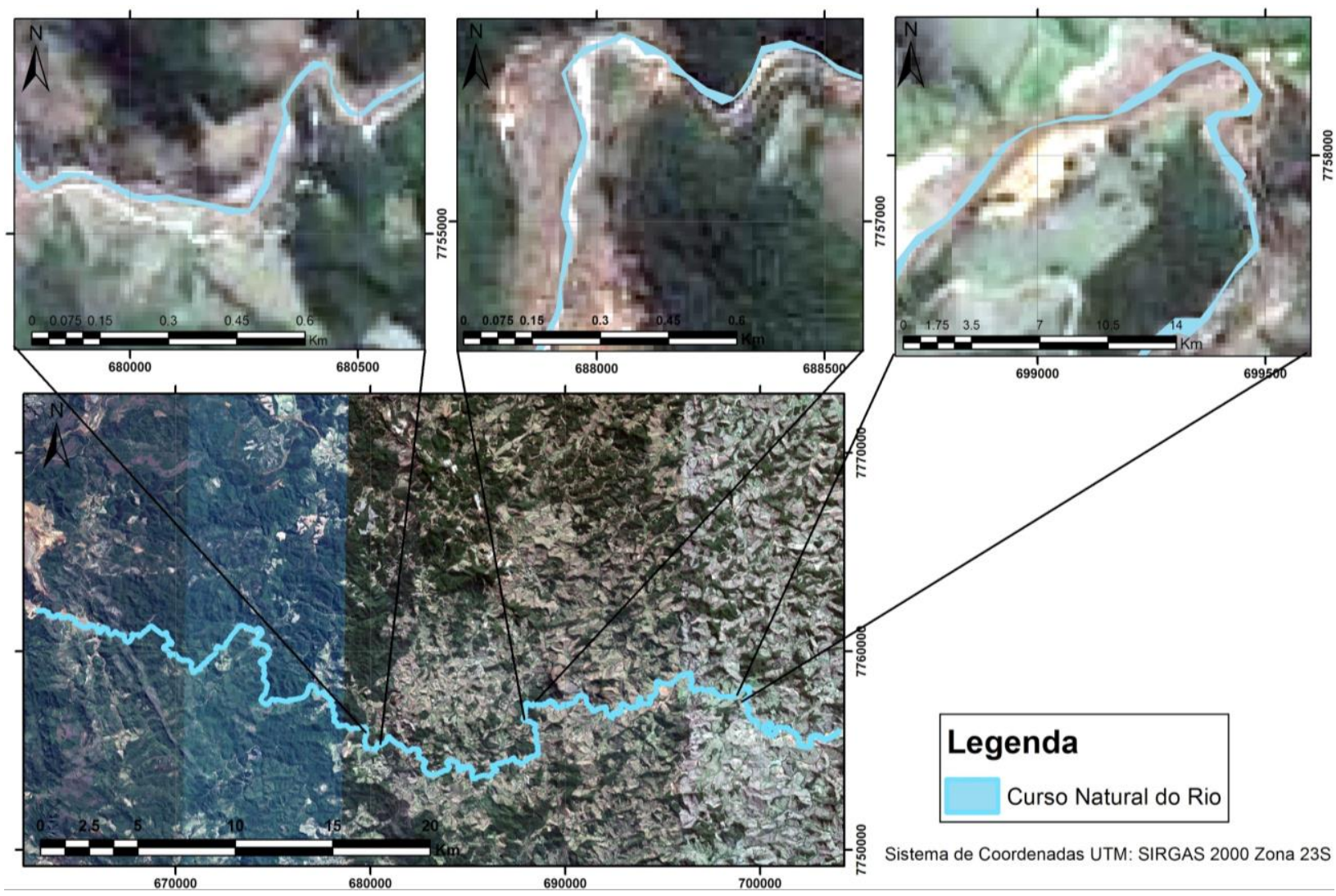

Fonte: Autores deste trabalho

Na Figura 4, consta a delimitação do curso modificado do rio, isto é, posterior ao rompimento da barragem, obtido por meio da imagem na data de 09/08/2016. Quando comparada com a Figura 1, vemos que nos trechos em que foram ampliadadas, o curso natural foi bastante alterado. Essa alteração fica mais nítida na Figura 5, que demonstra como o rio se encontra atualmente, bem como suas margens. Através de cálculos feitos pelo ArcGIS, cerca de $130 \mathrm{Km}$ do rio foi transfigurado, remodelando o curso natural do rio. 
Figura 04 - Rio Gualaxo do Norte após do rompimento da Barragem Fundão: Trecho Bento Rodrigues - Barra Longa

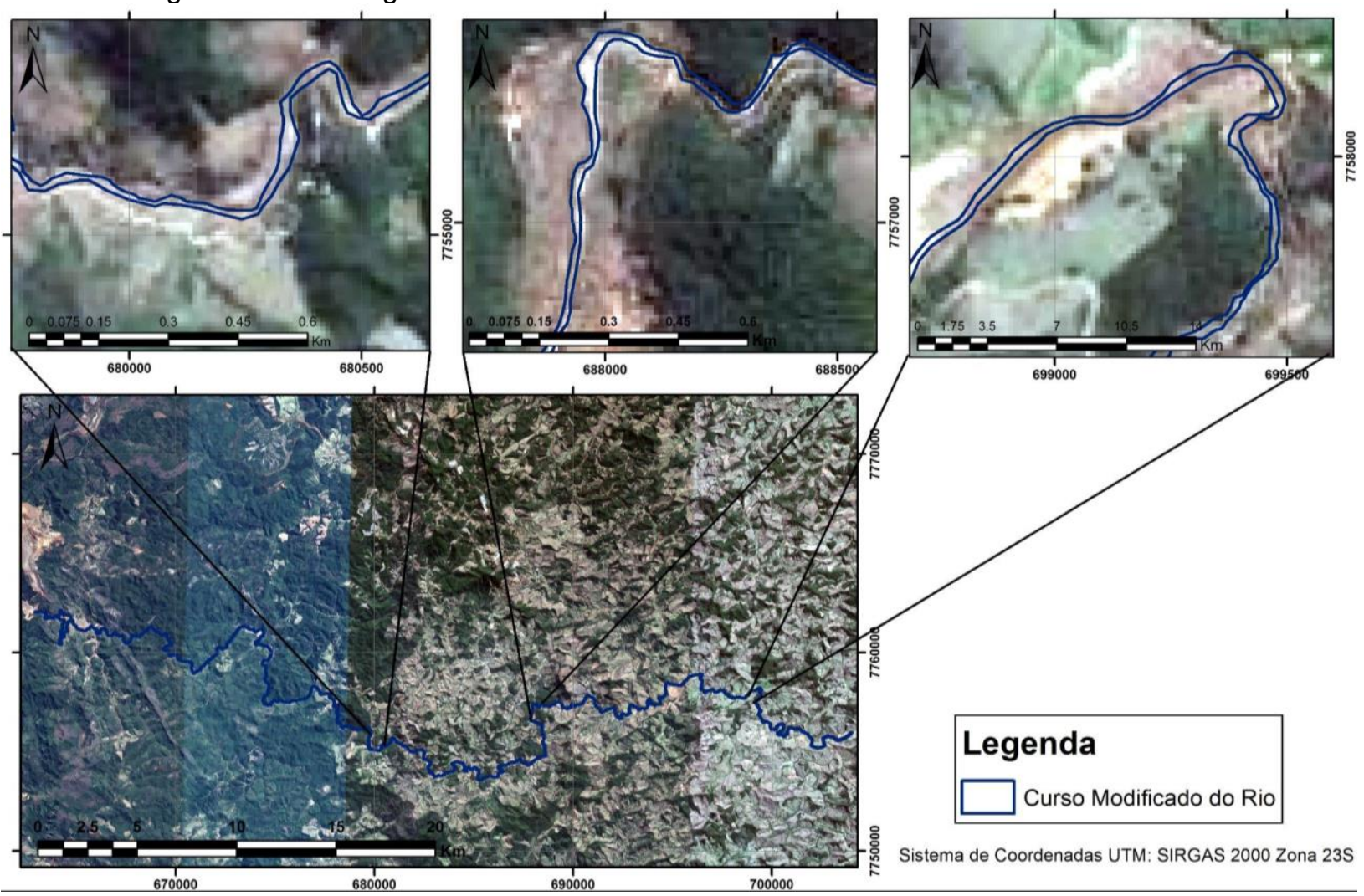

Fonte: Autores deste trabalho

Já na Figura 5, demonstra mais nitidamente as conturbações sofridas pelo rio, nas parte onde foi dado zoom, pode-se ver o curso natural e o curso modificado sobrepostos, evidenciando as transformações no seu trajeto. O polígono azul claro é o curso natural, o azul escuro é o curso atual e a parte marrom, é a nova margem, após a passagem do "mar de lama", proveniente do rompimento da barragem.

Após todos esses mapas, é possível identificar como que o acontecimento afetou o percurso do rio, sendo que grandes áreas foram afetadas, modificando a paisagem, aumentando as margens e afetando desfavoravelmente a biota da região. Todos esses impactos ficaram nítidos nas imagens, sendo assim, vemos que o rompimento da barragem, impactou de forma significativa, todo o trajeto do rio em estudo.

No trabalho desenvolvido por Mendes e Felippe (2016), já se vislumbrava a modificação de toda a dinâmica fluvial da região, com a alteração da quantidade de sedimentos que o rio transporta e a intensificação do processo de formação de depósitos ao longo de todo o rio Doce. Mesmo avaliando apenas um trecho inicial, estas alterações puderam ser confirmar com este trabalho. 
Figura 05 - Rio Gualaxo do Norte após rompimento da Barragem Fundão: Trecho Bento Rodrigues - Barra Longa

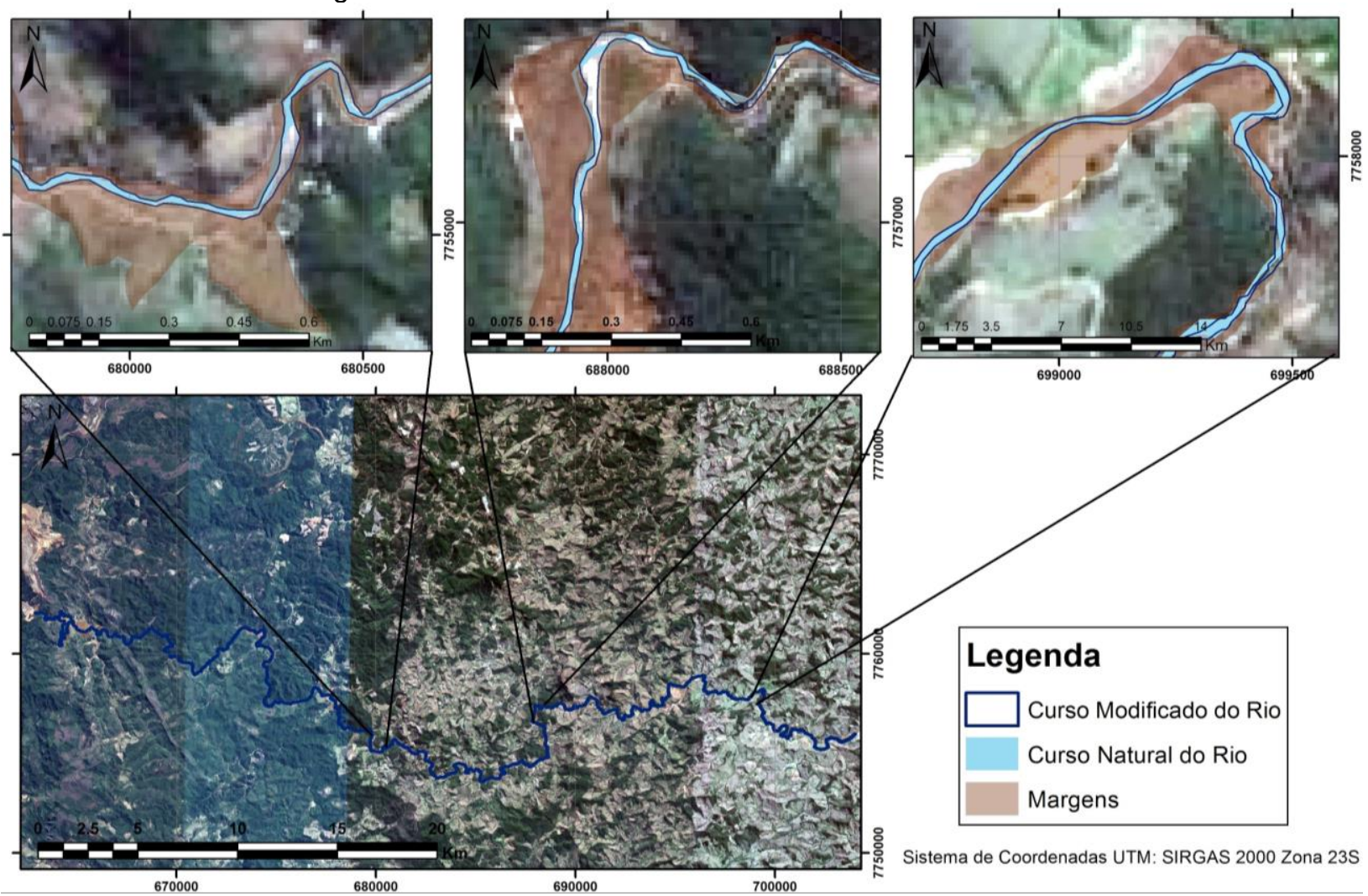

Fonte: Autores deste trabalho

Além do depósito de sedimentos no leito de inundação do rio e da desconfiguração do leito original pela onda de rejeitos, sendo estes fatores de alteração imediata, a grande concentração de sedimentos na água do rio, após o ocorrido, constatado pelo trabalho de Costa et. al (2018), também contribui para a modificação do curso, com o depósito destes ao longo da calha, proporcionando uma alteração mais lenta, mas muito superior à alteração que o leito teria, caso não houvesse o rompimento.

\section{CONCLUSÕES}

O rompimento da barragem Fundão no município de Mariana - MG afetou inúmeras nascentes, contaminou e modificou o curso de rios, como o Gualaxo do Norte, rio do Carmo e Doce. Além de destruir florestas que estavam situadas em Áreas de Preservação Permanente. A bacia hidrográfica do rio Doce foi contaminada pelos rejeitos e consequentemente os níveis de turbidez da água foram elevados, afetando a população de peixes de todos os cursos d'água atingidos pela lama. O 
rio Gualaxo do Norte, assim como os outros rios, sofreu modificações devido a onda de rejeito de minério que o atingiu. Até os dias atuais, percebe-se que em vários trechos do rio, o curso ainda está alterado se comparado ao curso natural (como era antes do rompimento da barragem), esta alteração se deu em uma escala muito maior do que a alteração ocorrida naturalmente ao longo dos anos. Alterações destas magnitudes afetam diretamente todo o ecossistema local, como por exemplo as comunidades de peixes que buscam regiões com as menores velocidades de fluxo para desova, plantas aquáticas anfíbios entre outros. Deste modo, foi possível notar que os resultados alcançados com este trabalho demonstram um impacto que poderia não ser bem dimensionado, mas que devido ao emprego da metodologia adotada pôde ser quantificado.

\section{REFERÊNCIAS}

ALVES, J. M. P.; CASTRO, P. T. A.. Influencia de Feições Geológicas na Morfologia da Bacia do Rio do Tanque (MG) Baseada no Estudo de Parametros Morfométricos e Análise de Padrões de Lineamentos. Revista Brasileira de Geociências, v. 33, n.2, p.117-124, 2003.

BARBOUR, M.T., J. GERRITSEN, B.D. SNYDER, AND J.B. STRIBLING. Rapid Bioassessment Protocols for Use in Streams and Wadeable Rivers: Periphyton, Benthic Macroinvertebrates and Fish. 2 ${ }^{\underline{a}}$ ed. EPA 841-B-99-002. U.S. Environmental Protection Agency; Office of Water; Washington, D.C, 1999.

BIZZO, M. R.; MENEZES, J.; ANDRADE, S. F.. Protocolos de Avaliação Rápida de Rios (PAR). Caderno de Estudos Geoambientais CADGEO. v.04, n.01, p.05-13, 2014.

BRASIL. Decreto n. 46.892, de 20 de nov. de 2015. Dispõe sobre o levantamento dos danos e sugestões de medidas corretivas e restauradoras a serem executadas para a recuperação dos municípios atingidos e da Bacia do Rio Doce. Relatório. Minas Gerais, p. 9-9, nov. 2015. Disponível em:

http://www.cidades.mg.gov.br/images/NOTICIAS/2016/relatorio_final.pdf. Acesso em: 09 jun. 2018.

CALDEIRA, C. R. T.. Detecção de mudanças no entorno de reservatórios a partir de série temporal de imagens orbitais. Dissertação (Mestrado) - Curso Ciências Cartográficas, UNESP. Presidente Prudente: [s.n.], 2016138 f.

COPPIN, Pol et al. Review ArticleDigital change detection methods in ecosystem monitoring: a review. International Journal of Remote Sensing, v. 25, n. 9, p. 1565-1596, 2004.

COSTA, A. S. V.; VASCONCELLOS, C. D. O.; BRAVIN, T. C.. Análise das Alterações dos Parâmetros de Qualidade da Água do Rio do Carmo, Afluente do Rio Doce, Após Rompimento da Barragem de Fundão, em Mariana-MG. Holos Environment, n. 18, v. 2, p. 160176, 2018. 
FREITAS, C. M.; SILVA, M. A.; MENEZES, F.. O desastre na barragem de mineração da Samarco: Fratura exposta dos limites do Brasil na redução de risco de desastres. Ciência e Cultura, n. 3, v. 68, p. 25-30, 2016.

GONÇALVES, J. L. G.; FRANCISCO, P. R. M.; VIEIRA, E. N. de L. Identificação de áreas degradadas através de técnicas de detecção de mudanças. In: CONGRESSO NORTE NORDESTE DE PESQUISA E INOVAÇÃO, 8., 2013. Anais...Salvador, 10 p., 2013.

MENDES, L. C.; FELIPPE, M. F.. A Geomorfologia do Tecnógeno e Suas Relações com o Rompimento da Barragem Fundão (Mariana, Minas Gerais). Revista de Geografia PPGEO - UFJF. Juiz de Fora, v.6, n.4, p.353-362, 2016.

MERTERNS, B.; LAMBIN, E.F.. Land-Cover-Change Trajectories in Southern Cameroon. Annals of the Association of American Geographers, 90, 467-494, 2000.

NETO, A. F. R.; ALVES, S. G.; ARAÚJO, M. S. B.; SILVA, C. E. M.. Caso Samarco em Mariana/MG e Ação Civil Pública: Busca Pelo Meio Ambiente Ecologicamente Equilibrado. Revista Gestão \& Sustentabilidade Ambiental, Florianópolis, v. 7, n. 1, p. 315-328, 2018.

NOFFS, P.S.; GALLI, L.F.; GONÇALVES, J.C. Recuperação de áreas degradadas da mata atlântica: Uma experiência da CESP - Companhia Energética de São Paulo. (Caderno, 3) Disponível em: http://www.rbma.org.br/rbma/pdf/caderno_03.pdf. Acesso em: 01 de jun. 2018.

OLIVEIRA, A. M. S. Estudos sobre o Tecnógeno do Brasil. ENCONTRO DE TECNÓLOGOS. ABEQUA, 1., 2005. Anais... 2005. Disponível em:

http://www.abequa.org.br/mostra_sessao.php?sessao=27. Acesso em: 22 jul. 2016.

PONTES, N.. Mariana completa seis meses sob a lama. DW Made for minds. 2016. Disponível em: http://www.dw.com/pt-br/mariana-completa-seis-meses-sob-a-lama/a-19232712. Acesso em: 08 jun. 2018.

RODRIGUES, A.S.L.; CASTRO, P.T.A.; MALAFAIA, G. Utilização dos Protocolos de Avaliação Rápida de Rios como Instrumentos Complementares na Gestão de Bacias Hidrográficas Envolvendo Aspectos da Geomorfologia Fluvial: Uma Breve Discussão. Enciclopédia Biosfera - Centro Científico Conhecer, Goiânia, v.6, n.11, p. 1-9, 2010.

SILVA, G. F.; CARVALHO, M. V. A.; CRUZ, C. B. M., Análise Espaço-Temporal do Desastre Ambiental em Mariana-MG a Partir das Geotecnologias. Revista Continentes (UFRRJ), ano 7, n. 13, p. 49-77, 2018.

VIEGAS, J. C.; RODRIGUES, T. C. S.; RODRIGUES, M. S. Detecção de mudanças na cobertura do solo na área de influência da cidade de Pinheiro (Maranhão - Brasil), com o uso de sensores orbitais e SIG's. Reencontro de Saberes Territoriales Latinoamericanos Perú, 2013.

WECKMÜLLER, R.; SLOVINSCKI, N. C.; VICENS, R. S. Análise multitemporal como subsídio à identificação da trajetória evolutiva do uso e cobertura da terra no corredor ecológico do Muriqui/RJ. Revista Brasileira de Cartografia, v. 65, n. 03, p.467-477, 2013.

ZANI, M. V.; ABREU, M. B.; CRUZ, C. B. M. Detecção de mudanças no período de 1994 a 2007 nos remanescentes florestais na Região Turístico-Cultural do Médio Paraíba - RJ. SIMPÓSIO BRASILEIRO DE SENSORIAMENTO REMOTO - SBSR, 15., 2011. Anais... Curitiba, PR, Brasil, 30 de abril a 05 de maio de 2011, INPE p. 2905. 